\title{
TENSILE PROPERTIES OF AMORPHOUS DIAMOND FILMS
}

D.A. LaVAN, R.J. HOHLFELDER, J.P. SULLIVAN, T.A. FRIEDMANN, M. MITCHELL, C.I.H. ASHBY

Sandia National Labs, Albuquerque, NM 87185, dalavan@sandia.gov

\section{ABSTRACT}

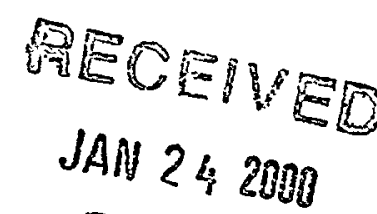

The strength and modulus of amorphous diamond, a new material for surface micromachined MEMS and sensors, was tested in uniaxial tension by pulling laterally with a flat tipped diamond in a nanoindenter. Several sample designs were attempted. Of those, only the single layer specimen with a 1 by $2 \mu \mathrm{m}$ gage cross section and a fixed end rigidly attached to the substrate was successful. Tensile load was calculated by resolving the measured lateral and normal forces into the applied tensile force and frictional losses. Displacement was corrected for machine compliance using the differential stiffness method. Post-mortem examination of the samples was performed to document the failure mode. The load-displacement data from those samples that failed in the gage section was converted to stress-strain curves using carefully measured gage cross section dimensions. Mean fracture strength was found to be $8.5 \pm 1.4 \mathrm{GPa}$ and the modulus was $831 \pm 94 \mathrm{GPa}$. Tensile results are compared to hardness and modulus measurements made using a nanoindenter.

\section{INTRODUCTION}

Amorphous diamond has shown promise as an alternative to polysilicon for surface micromachined MEMS and sensors. Improved wear resistance, stiction, strength and fracture toughness have been reported. Deposition techniques developed at Sandia have allowed true MEMS devices to be fabricated. Several authors have published mechanical properties extracted from indentation testing for similar materials. A direct testing technique, developed to characterize the strength and distribution in properties of polysilicon, was applied to measure the strength and modulus of samples of amorphous diamond having dimensions typical of critical features of MEMS devices. This technique will be described as well as the results for the amorphous diamond MEMS. The results will be compared to indentation results on material from the same die.

\section{EXPERIMENT}

\section{Material Description}

Recent work [1, 2] has shown that thermally stable, stress-free, smooth, hard, and stiff amorphous-diamond films can be grown using pulsed laser deposition at room temperature followed by a brief anneal at $600^{\circ} \mathrm{C}$. Layers $1 \mu \mathrm{m}$ thick were built up by depositing 4 layers of amorphous diamond ( $\sim 0.25 \mu \mathrm{m}$ thick) by repeated deposition and annealing in situ. The films were than post annealed in a vacuum furnace $\left(550^{\circ} \mathrm{C}\right.$ for $\sim 60 \mathrm{hrs}$ ) until the residual stress (as measured by wafer curvature) was reduced to near zero ( $<10 \mathrm{MPa}$ ). The tensile properties of these films are expected to approach those of natural diamond, but they have not been directly measured. Amorphous diamond MEMS structures were patterned using contact lithography on silicon wafers that were prepared with a $2 \mu \mathrm{m}$ blanket layer of $\mathrm{SiO}_{2}, 60 \mathrm{~nm}$ of polysilicon for adhesion and $1 \mu \mathrm{m}$ of amorphous diamond. 


\section{DISCLAIMER}

This report was prepared as an account of work sponsored by an agency of the United States Government. Neither the United States Government nor any agency thereof, nor any of their employees, make any warranty, express or implied, or assumes any legal liability or responsibility for the accuracy, completeness, or usefulness of any information, apparatus, product, or process disclosed, or represents that its use would not infringe privately owned rights. Reference herein to any specific commercial product, process, or service by trade name, trademark, manufacturer, or otherwise does not necessarily constitute or imply its endorsement, recommendation, or favoring by the United States Government or any agency thereof. The views and opinions of authors expressed herein do not necessarily state or reflect those of the United States Government or any agency thereof. 


\section{DISCLAIMER}

Portions of this document may be illegible in electronic image products. Images are produced from the best available original document. 
Direct tensile measurements on structural thin films are challenging. A technique to perform automated testing has been developed that utilizes the lateral force capabilities of a nanoindenter to measure the small forces and displacements. Typical samples produced from polysilicon incorporate a freely rotating hub on the fixed end of the sample to avoid bending stresses on the sample $[3,4]$. Two designs were attempted in amorphous diamond, a single layer sample utilizing a timed release of the underlying oxide, and a two layer structure with a patterned oxide between the two amorphous diamond layers. Difficulty in fabrication limited the samples to the former, simpler, style.

Double ended "dog bone" shaped samples were used, where one end is attached to the silicon die via a layer of $\mathrm{SiO}_{2}$. The mask was designed so that the fixed ends would not release during a timed etch of sufficient duration to release the gage section and the ring used to engage the nanoindenter. Figure 1 shows two views of tested samples. The partially etched $\mathrm{SiO}_{2}$ is visible through the amorphous diamond layer under the fixed ends of the samples.
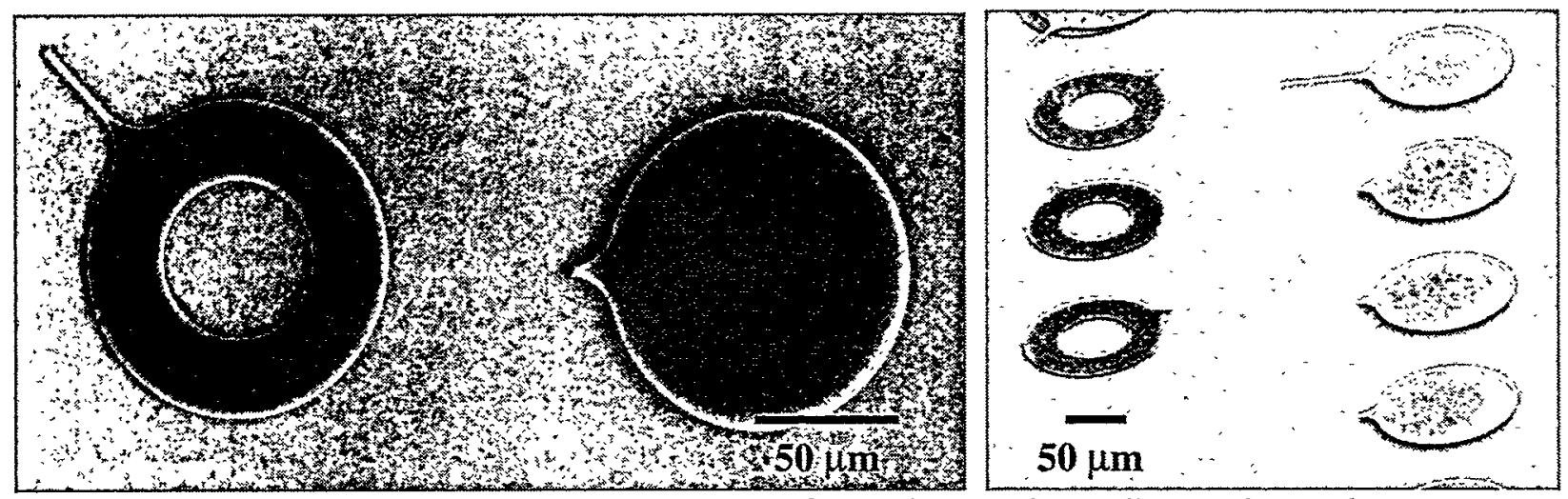

Figure 1. Top and perspective views of tested amorphous diamond samples.

The sample widths and lengths were measured in an SEM and compared to a calibration standard. The thickness was measured using a profilometer. For this group of samples, $w=2.25$ $\mu \mathrm{m}$ and $\mathrm{t}=1.02 \mu \mathrm{m}$. The raw load-displacement data is processed in two steps to evaluate the strength and modulus of the material. First, a force balance is solved to correct for the losses due to the frictional sliding of the tip along the substrate. The diamond tip is a flat-bottomed cone with an included angle, $2 \theta$, of $59^{\circ}$. The normal force, $\mathrm{N}$, and lateral force, $\mathrm{L}$, are recorded and must be resolved into the tensile force on the sample, $\mathrm{T}$, the reaction due to the tip angle normal to the surface, $\mathrm{N}_{\mathrm{r}}$, and the frictional losses, $\mathrm{L}_{\mathrm{f}}$ :

$$
\begin{aligned}
& L_{f}=\mu N_{f} \\
& L=T+L_{f} \\
& N=N_{r}+N_{f} \\
& N_{r}=\frac{T}{\tan \theta}
\end{aligned}
$$

Secondly, the measured displacement must be corrected for machine compliance. The total measured compliance is the sum of the machine compliance (including grips, etc) and the compliance due to the tensile gage length. Testing samples with identical cross sectional 
dimensions and several lengths provides a simple and accurate way to evaluate the machine compliance $[5,6]$.

$$
\frac{1}{K_{\exp }}=\frac{1}{K_{\text {machine }}}+\frac{1}{K_{\text {gage }}}
$$

$K_{\text {machine }}$ is evaluated from the intercept of a linear least squares fit of $1 / K_{\exp }$ versus sample length. The modulus is determined from $\mathrm{K}_{\text {gage }}$, the sample gage length and the cross sectional area:

$$
E=\frac{l K_{\text {gage }}}{A}
$$

\section{RESULTS}

The mean strength and standard deviation for the 28 samples tested is $8.5 \pm 1.4 \mathrm{GPa}$. Because the shortest samples had the largest error in the modulus measurements (there was little difference between the machine compliance and the total compliance), they were not considered when calculating the average. The average modulus for the $18100-$ and $500-\mu \mathrm{m}$ long samples is $831 \pm 94 \mathrm{GPa}$. Figure 2 depicts the strength and modulus for all the samples plotted as a function of length, the average is constant, which is expected.
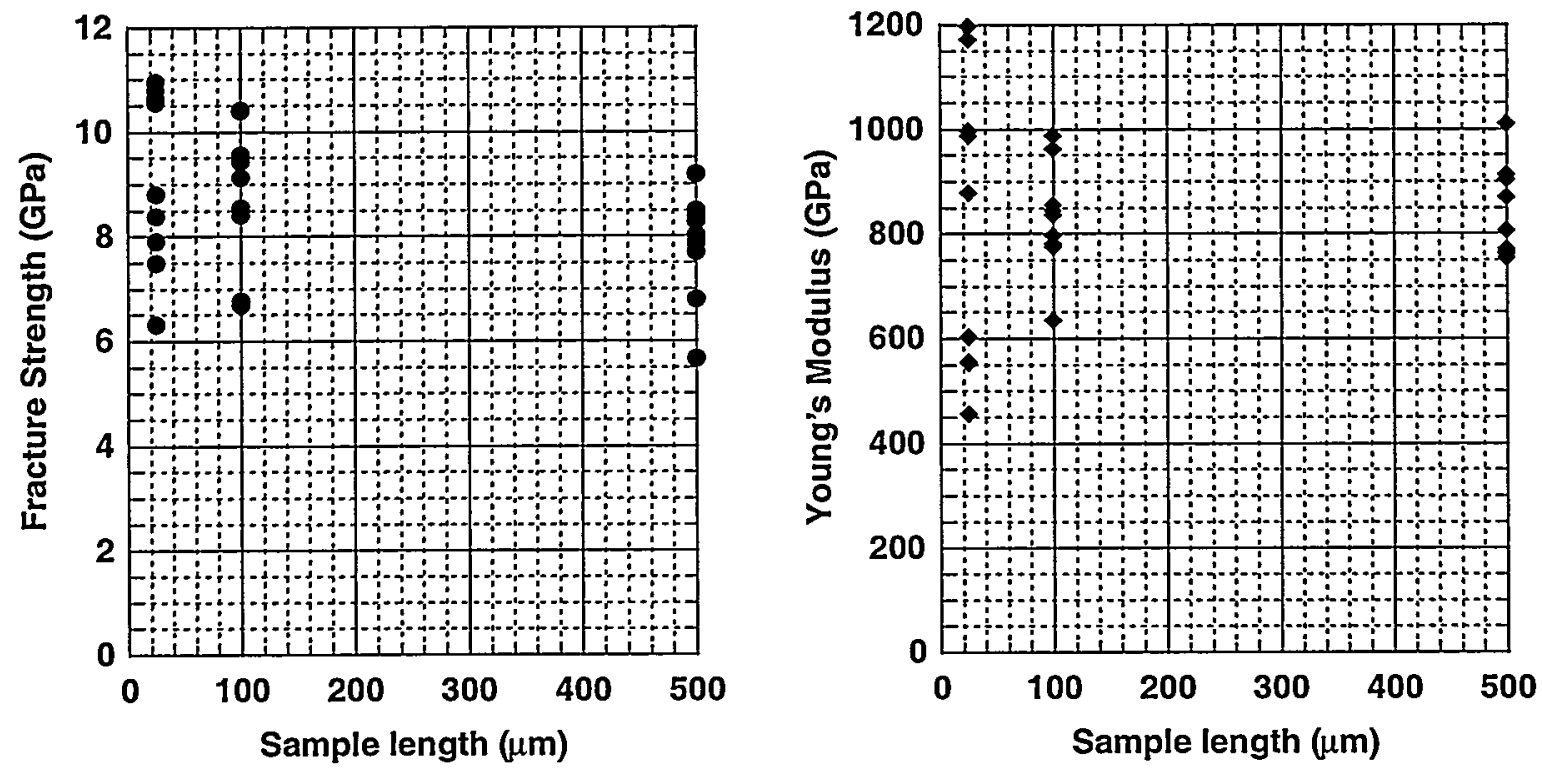

Figure 2. Strength and modulus for amorphous diamond samples as a function of length.

Since the reliability of brittle materials is governed by the probability of finding a critical size defect, the strength data is examined using a statistical approach. Weibull analysis [7] of strength was performed. While 28 data points are sufficient to calculate the distribution, more tests will be performed to evaluate a three parameter Weibull fit that includes sample volume. A probability estimator in the form of $(\mathrm{j}-0.5) / \mathrm{n}$ was chosen [8]. The data is plotted in Figure 3. The Weibull modulus, $\mathrm{m}$, was calculated to be 7.4 , but the data grouped into several strength levels which suggests that multiple failure modes were operative. These different failure modes could result from several sources: defects in film deposition, errors in lithography, errors in testing, etc. Post mortem examination of the samples did not reveal a pattern. 

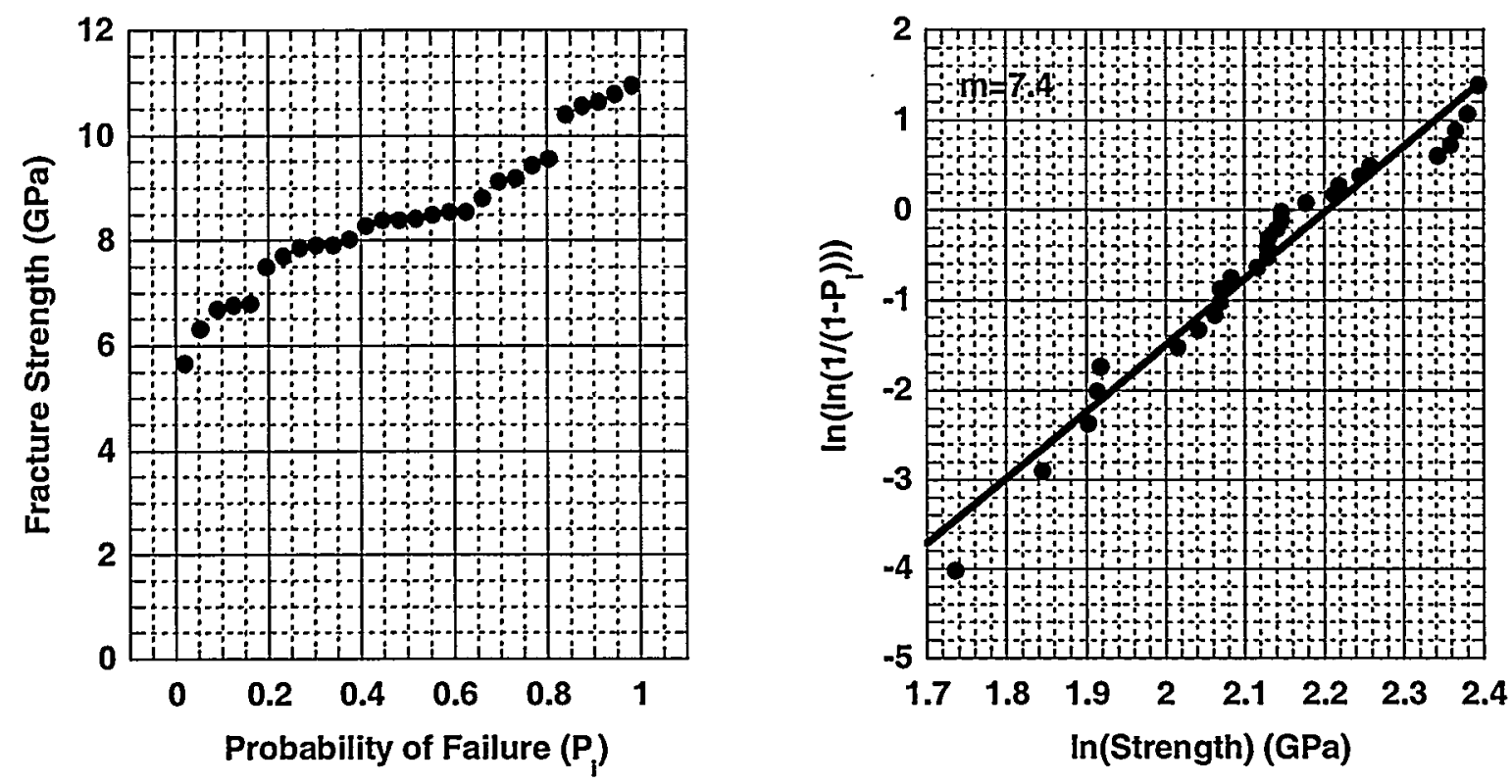

Figure 3. Weibull representation of strength data for amorphous diamond samples.

\section{$\underline{\text { Nanoindentation }}$}

Nanoindentation experiments were conducted on the amorphous diamond film using a Berkovitch tip indenter. Great care was taken to calibrate the tip area function prior to the thin film testing; the first term of the optimization was not constrained, all nine terms of the polynomial fit were calculated based on the fused silica data. 10 indents were performed at a constant strain rate (constant load/load rate) to a depth of $250 \mathrm{~nm}$. The data was averaged into bins, according to depth, in $5 \mathrm{~nm}$ increments. Figure 4(a) depicts the average load-displacement curve. The minimal difference between the loading and unloading curves indicates that there is little plastic deformation. Figure 4(b) and (c) are the hardness and modulus as a function of depth found using the conventional Oliver-Pharr analysis [9]. Considering the data at $150 \mathrm{~nm}$ depth, the hardness is $65 \pm 7 \mathrm{GPa}$. The peak value for modulus is $500 \pm 100 \mathrm{GPa}$.

Indentation testing of amorphous diamond is prone to error since the material approaches the hardness of the diamond tip. The load-displacement data can be modeled to account for the substrate and tip compliance, as is done with a 2-D ABAQUS model in [10]. The calculated hardness is $84 \pm 4 \mathrm{GPa}$ and the calculated modulus is $980 \pm 34 \mathrm{GPa}$ [11].

\section{DISCUSSION}

Direct measurements of the properties of amorphous diamond MEMS have shown that the tensile strength and modulus are significantly higher than those of polysilicon, the current standard material for surface micromachined MEMS. The mean strength is twice that reported for polysilicon produced at Sandia and measured with the same technique as described in this paper. The mean strength is 2 to 5 times that reported for polysilicon from other sources and using other test techniques [12]. 


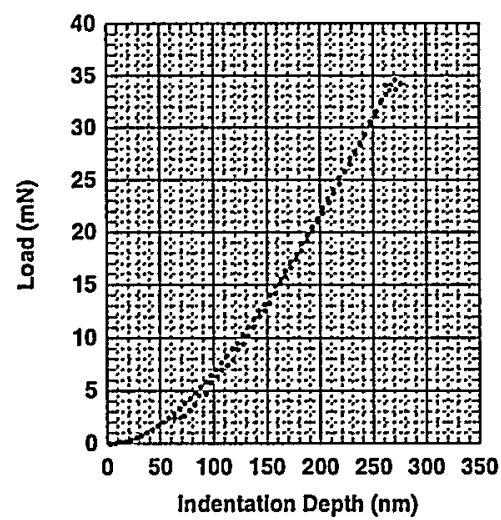

(a)

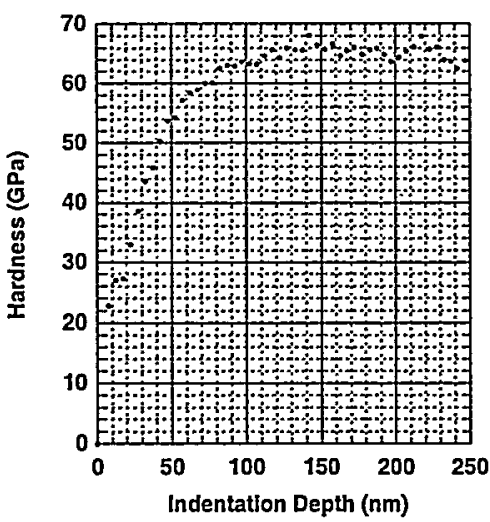

(b)

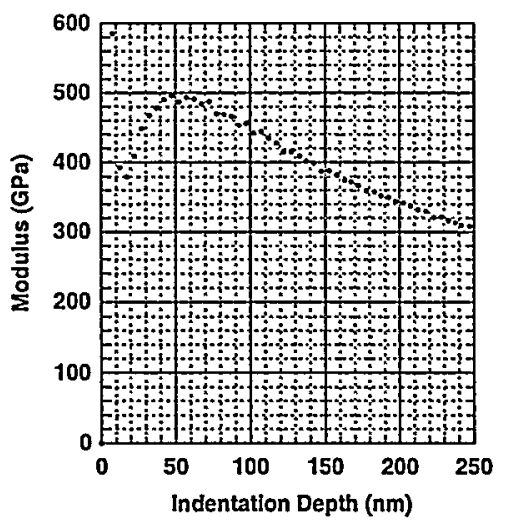

(c)

Figure 4. Nanoindentation data for $1 \mu \mathrm{m}$ thick amorphous diamond film. Averages from ten indents. (a) Load-displacement (b) Hardness (c) Modulus.

The modulus is much higher, five times that of polysilicon $(\sim 163 \mathrm{GPa})$ and is about $20 \%$ less than that expected for cubic diamond ( 1020 GPa) [13]. While there is much experience in producing high quality polysilicon, amorphous diamond is still at an experimental level. As is typical in the semiconductor fabrication industry, deposition and lithography defects will be reduced and the measured strength is expected to increase as fabrication techniques continue to improve.

\section{ACKNOWLEDGEMENTS}

This work was supported under the Laboratory Directed Research and Development (LDRD) Program at Sandia National Lab. Sandia is a multiprogram laboratory operated by Sandia Corporation, a Lockheed Martin Company, for the United States Department of Energy under Contract DE-AC04-94AL85000.

\section{REFERENCES}

1. Sullivan, J.P., T.A. Friedmann, and A.G. Baca, J. Electronic Materials, 26, pp. 1021-1029 (1997).

2. Friedmann, T.A., J.P. Sullivan, J.A. Knapp, D.R. Tallant, D.M. Follstaedt, D.L. Medlin, P.B. Mirkarimi, Applied Physics Letters, 71, pp. 3820-3822 (1997).

3. LaVan, D.A. and T.E. Buchheit in MEMS Reliability for Critical and Space Applications, (SPIE Proc. 3880, 1999), pp. 40-44.

4. LaVan, D.A. and T.E. Buchheit in Materials Science of Microelectromechanical Systems (MEMS) II, (MRS Proc. 1999), submitted.

5. Greek, S., F. Ericson, S. Johansson, J. A. Schweitz in Thin Films: Stresses and Mechanical Properties VI, (MRS Proc. 1997), pp. 227-232.

6. Greek, S., F. Ericson, S. Johansson, M. Furtsch, A. Rump, J. Micromech Microeng, 9, pp. 245-251 (1999).

7. Weibull, W., Proceedings Royal Swedish Institute for Engineering Research, 151, pp. 145 (1939).

8. Sullivan, J.D. and P.H. Lauzon, J. Materials Science Letters, 5, pp. 1245-1247 (1986). 
9. Oliver, W.C. and G.M. Pharr, J. Materials Research, 7, pp. 1564-1583 (1992).

10. Knapp, J.A., D.M. Follstaedt, S.M. Myers, J.C. Barbour, T.A. Friedmann, J. Applied Physics, 85, pp. 1460-1474 (1999).

11. Knapp, J., private communication, 1999.

12. Sharpe, W.N., Jr., S. Brown, G.C. Johnson, W. Knauss in Microelectromechanical Structures for Materials Research, (MRS Proc. 518, 1998), pp. 57-65.

13. Simmons, G. and H. Wang, Single Crystal Elastic Constants and Calculated Aggregate Properties. 2nd ed., The MT Press, Cambridge, 1971. 